Open Access

\title{
Factors associated with early resumption of sexual intercourse among postnatal women in Uganda
}

\author{
Alice C. Alum', Irene B. Kizza², Charles P. Osingada' ${ }^{1}$ Godfrey Katende ${ }^{2}$ and Dan K. Kaye ${ }^{3^{*}}$
}

\begin{abstract}
Background: Despite being a key component to be addressed during postnatal period, sexuality has long been a subject of secrecy and taboo in Africa. Resumption of sexual intercourse after giving birth has been shown to reduce extramarital affairs and consequently reduce risk of sexually transmitted infections like HIV/AIDS. Consequences of early resumption of sexual intercourse include unwanted pregnancy, genital trauma and puerperal infection. The objective of the study was to assess prevalence and factors associated with early resumption of sexual intercourse among postnatal mothers attending postnatal clinic at a National referral Hospital in Uganda.

Methodology: A cross-sectional study that employed an interviewer-administered questionnaire was conducted among 374 women who delivered six months prior to conducting the study. The independent variables included socio-demographic characteristics of the participant, socio-demographic characteristics of the spouse, perceived cultural norms, medical history, mode of delivery, and postpartum complications. The dependent variable was timing of resumption of sexual intercourse after childbirth (before or after six weeks postpartum). Data were analysed using SPSS version 16.0.
\end{abstract}

Results: The study showed that 105 participants (21.6\%) had resumed sexual intercourse before 6 weeks after childbirth. The participants' education level, occupation, and parity; education level of the spouse, age of baby and use of family planning were the factors associated with early resumption of sexual intercourse after child birth (before six weeks postpartum) $(p<0.05)$.

Conclusion: Many women resumed sexual intercourse after six weeks. Women with high income, low parity, who ever-used contraception or had a spouse with high education level were more likely to have early resumption of sexual intercourse.

\section{Introduction}

The postnatal period (the time just after delivery and through the first six weeks of life) is especially critical for newborns and mothers as most deaths of mothers and babies occur within this period [1-3]. This is an ideal time to deliver interventions that improve the health and survival of both the newborn and the mother [3]. Adong in her study about knowledge, perceptions and practices in pregnancy and childbirth in Uganda [4], reported that postnatal care services were poor or absent. In developed countries, virtually all women and

\footnotetext{
* Correspondence: dankkaye@yahoo.com

${ }^{3}$ Department of Obstetrics and Gynecology, School of Medicine, College of Health Sciences, Makerere University, P.O. Box 7072, Kampala, Uganda

Full list of author information is available at the end of the article
}

their infants receive postpartum and postnatal care. Yet in developing countries, policies and programs have largely overlooked this critical time, hindering efforts to meet the Millennium Development Goals (MDGs) for maternal and child survival [3]. The World Health Organization (WHO) recommends that with limited resources, contact with the healthcare system postpartum would be at least during the first twenty four hours and before the end of the first week [2]. However, a review of postnatal services found that the nature and frequency of this care varies considerably [2, 5-10]. Indeed, many women who give birth are discharged within hours after child birth without any indication where they can obtain further care or support [11]. 
Sexuality is one of the key components to address during postnatal period; it has long been a subject of secrecy and taboo in Africa [12]. This is particularly true of sensitive issues such as postnatal sexual intercourse. Perceived sexual problems in the post-partum period need to be addressed [13, 14]. These are dyspareunia, lack of vaginal lubrication, difficulty in achieving orgasm, vaginal loosening, loss of sexual desire and bleeding or irritation after sexual intercourse [15]. Resumption of sexual intercourse after giving birth has been shown to allow the men to "stay more at home" (not to get extramarital affairs) which reduces the risk of sexually transmitted infections like HIV/AIDS infections [16]. The consequences of early resumption of sexual intercourse on the other hand, include unwanted pregnancy which may be undesirable especially if no contraceptive method is used after six months postpartum [16]. Moreover, postpartum abstinence is perceived as being against natural human sexuality and results in practices that could endanger family relationships and health, especially in the era of HIV/ AIDS $[8,17]$.

African women tend to follow established community norms and traditions in making decisions that influence resumption of sexual intercourse after giving birth [18]. Studies have shown that early initiation of sexual intercourse was observed in women who had spontaneous vaginal delivery and in those who stayed at home with their mothers, than in-laws and aunts [15]. Standard guidelines published by Ministry of Health in Uganda recommend that, mothers abstain from sexual intercourse for at least 6 weeks after child birth as the risk of infecting the baby through breast milk is higher if the mother is newly HIV positive [19]. For example, the risk of motherto-child HIV transmission was 2.9-fold higher during the postpartum period among those who had recently acquired HIV than among those with chronic HIV infection, and 2.3-fold higher during the pregnancy/postpartum periods combined [20]. Postpartum women may be at greater risk for infections due to vaginal lesions and abrasions following labour and delivery process [21]. Anecdotal reports indicate that some mothers request not to be discharged quickly from hospital following childbirth for fear of being forced to have sexual intercourse by their partners before they heal. Additionally it has been observed that some women return to hospital with gaping episiotomies in the postnatal period, one indication that they had engaged in sexual intercourse before the perineum was completely healed [19]. Women need adequate counseling to be prepared for resumption of sexual intercourse postpartum to avoid complications such as puerperal infection and unwanted pregnancies. The extent to which postnatal mothers adhere to recommended guidelines is not documented. The purpose of our study was to assess the timing of resumption of sexual intercourse after childbirth and factors associated with early resumption. Information generated could guide service providers on how to improve the information given to women and their partners during antenatal care and after childbirth regarding postpartum resumption of sexual intercourse.

\section{Methods}

\section{Study setting and participants}

This cross-sectional study was conducted in the postnatal and immunisation clinics in Mulago National Referral and Teaching Hospital, Uganda. The Hospital has three postnatal and immunisation clinics, one for private clients (in lower Mulago) and the other two for general clients (in upper Mulago). About 20 mothers in the extended postpartum period (up to six months postpartum) access services every day, and the clinics run 5 days a week. The services offered include postnatal examination, health education on family planning, family planning, screening for cervical cancer, and infant immunisation and growth monitoring. The study participants were postpartum women who came for postnatal care (after six weeks postpartum) or brought their babies for immunization (within six months postpartum).

\section{Sample size and variables}

Using an expected proportion of women who resumed sexual intercourse within the six weeks postpartum of $58 \%$ [8], an acceptable error of $5 \%$, a power of $80 \%$ and a significance level of $95 \%$, we estimated a sample size of 374 participants would be adequate for the study.

The study instruments included a pre-tested interviewer-administered questionnaire consisting of closed and open-ended questions. On the questionnaire, the independent variables included socio-demographic characteristics of the participant, socio-demographic characteristics of the spouse, perceived cultural norms, medical history, mode of delivery, and postpartum complications. The dependent variable was timing of resumption of sexual intercourse after childbirth (before or after six weeks postpartum). Resumption of sexual intercourse was defined as having the first penetrative sexual intercourse after childbirth. Resumption of sexual intercourse before six weeks postpartum was regarded as early resumption.

\section{Data analysis}

Descriptive statistics were used summarise findings: means and standard deviations for numerical variables, and frequencies and percentages for categorical variables. The prevalence of early resumption of sexual intercourse was computed as the proportion of participants who resumed sexual intercourse before end of six weeks postpartum. The timing of sexual intercourse resumption was categorized into resumption before 6 weeks (early) and after 6 weeks (recommended time). To assess factors 
associated with early resumption of sexual intercourse, we used the student $\mathrm{t}$-test for numerical variables and chisquare test for categorical variables. Binary logistic regression analysis was performed to determine the predictors of early resumption of sexual intercourse after child birth. For all analysis statistical significance was set at $\leq 0.05$.

\section{Ethical considerations}

Ethical clearance was sought from the Institutional Review Board of the School of Health Sciences Makerere University and Mulago Hospital Research and Ethics committee. Written informed consent was obtained from prospective participants before their participation. The participants were assured that their participation was totally voluntary and that if they chose not to participate in the study, it would not in any way affect the care they would receive.

\section{Results}

Table 1 shows the socio-demographic characteristics of the participants. The majority of the mothers $(88 \%)$

Table 1 Demographic characteristics (individual factors)

\begin{tabular}{|c|c|c|c|}
\hline Item & Response & Frequency & Per cent \\
\hline \multirow[t]{3}{*}{ Age of mother (years) } & $15-20$ & 39 & 10.4 \\
\hline & $21-35$ & 329 & 88 \\
\hline & $36-45$ & 6 & 1.6 \\
\hline \multirow[t]{4}{*}{ Tribe } & Ganda & 230 & 61.5 \\
\hline & Banyankole & 41 & 11 \\
\hline & Basoga & 12 & 3.2 \\
\hline & Others & 91 & 24.3 \\
\hline \multirow[t]{4}{*}{ Religion } & Protestant & 97 & 25.9 \\
\hline & Roman catholic & 211 & 56.4 \\
\hline & Muslim & 26 & 7 \\
\hline & Others & 40 & 10.7 \\
\hline \multirow[t]{5}{*}{ Education of respondent } & No formal education & 11 & 2.9 \\
\hline & Primary & 81 & 21.7 \\
\hline & Secondary & 255 & 68.2 \\
\hline & Diploma & 5 & 1.3 \\
\hline & Degree & 22 & 5.9 \\
\hline \multirow[t]{2}{*}{ Marital status } & Unmarried & 30 & 8.0 \\
\hline & Married/ living together & 344 & 92.0 \\
\hline \multirow[t]{4}{*}{ Occupation of respondent } & House wife & 209 & 55.9 \\
\hline & Self employed & 117 & 31.3 \\
\hline & Civil servant & 8 & 2.1 \\
\hline & Private & 40 & 10.7 \\
\hline \multirow[t]{4}{*}{ Parity of participant } & First & 50 & 13.4 \\
\hline & Second & 184 & 49.3 \\
\hline & Third & 115 & 30.8 \\
\hline & Fourth or more & 24 & 6.4 \\
\hline \multirow[t]{5}{*}{ Highest level attained by spouse } & No formal education & 3 & 0.8 \\
\hline & Primary & 74 & 19.8 \\
\hline & Secondary & 243 & 65.0 \\
\hline & Diploma & 21 & 5.6 \\
\hline & Degree & 33 & 8.8 \\
\hline \multirow[t]{4}{*}{ Occupation of spouse } & Self employed & 209 & 55.9 \\
\hline & Peasant farmer & 48 & 12.8 \\
\hline & Civil servant & 49 & 13.1 \\
\hline & Private & 68 & 18.2 \\
\hline
\end{tabular}


were aged between 21 and 35 years, with average age of 27 years. Of the participants, 230 (61.5\%) belonged to the Baganda tribe; 211 (56.5\%) were of the Catholic religious denomination; $255(68.2 \%)$ had attained secondary level of education; and 344 (92\%) were married or lived with spouses. One hundred and eighty four (49.3\%) had delivered their second child; and 243 (65\%) of their spouses had attained secondary level of education.

\section{Participants' obstetrical and sexual history}

As shown in Table 2, 264 participants (70.5 \%) had vaginal delivery with no tears, and 289 (77.3\%) of their babies were aged between 6 and 19 weeks old, implying that this is the period that had elapsed since delivery. Of the 374 participants, 105 (28.1\%) had already resumed sexual intercourse after childbirth. The timing of resumption of sexual intercourse ranged between 3 and 24 weeks. Among those who had resumed sexual intercourse, $23(21.9 \%)$ resumed before 6 weeks after childbirth and $82(78.1 \%)$ resumed after 6 weeks.

Among the participants who had not resumed sexual intercourse, 139 (51.7\%) wished to wait until 6 weeks, $74(27.6 \%)$ were not staying with the husbands, 37 (13.8\%) reported still feeling too tired, and 19 (6.9\%) reported receiving advice against early resumption from the doctor or midwife as the reasons for not resuming.

Table 2 Obstetrical history/practices

\begin{tabular}{|c|c|c|c|}
\hline Item & Response & Frequency & Percentage \\
\hline \multirow[t]{3}{*}{ Mode of delivery } & Vaginal no tearing & 264 & 70.1 \\
\hline & Vaginal (episiotomy/tear) with stitches & 66 & 17.6 \\
\hline & Caesarean section & 44 & 11.8 \\
\hline \multirow[t]{3}{*}{ Age of baby now } & Six to 11 weeks & 147 & 39.3 \\
\hline & 12 to 19 weeks & 142 & 38 \\
\hline & 20 to 24 weeks & 85 & 22.7 \\
\hline \multirow[t]{2}{*}{ Resumed sexual intercourse } & Yes & 105 & 28.1 \\
\hline & No & 269 & 71.9 \\
\hline \multirow[t]{2}{*}{ Timing of resumption } & Before 6 weeks & 61 & 21.6 \\
\hline & After 6 weeks & 221 & 78.4 \\
\hline \multirow[t]{2}{*}{ Reason for resuming sexual intercourse } & I wanted sex & 57 & 21.6 \\
\hline & Partner demand & 207 & 78.4 \\
\hline \multirow[t]{4}{*}{ Persons she lives with after childbirth } & Husband/partner & 233 & 87.9 \\
\hline & Mother in-law & 8 & 3.0 \\
\hline & Auntie & 16 & 6.0 \\
\hline & Mother & 8 & 3.0 \\
\hline \multirow[t]{4}{*}{ Reason for not resuming sexual intercourse } & Too tired & 8 & 13.8 \\
\hline & Doctor/midwife told me not to & 4 & 6.9 \\
\hline & Wanted to wait until 6 weeks & 30 & 51.7 \\
\hline & Not with husband & 16 & 27.6 \\
\hline \multirow[t]{2}{*}{ Using any family planning } & Yes & 93 & 26.5 \\
\hline & No & 258 & 73.5 \\
\hline \multirow[t]{5}{*}{ Problems noted after resuming sexual intercourse } & No problem & 177 & 75.6 \\
\hline & Pain/bruises during sexual & 26 & 11.1 \\
\hline & intercourse & & \\
\hline & Bleeding & 19 & 8.1 \\
\hline & Abdominal pain & 12 & 5.1 \\
\hline \multirow[t]{2}{*}{ Breastfeeding the baby } & No & 16 & 4.3 \\
\hline & Yes & 358 & 95.7 \\
\hline \multirow[t]{3}{*}{ Received health education/advice on when to resume sexual intercourse } & Not sure whether given & 89 & 23.8 \\
\hline & No advice given & 245 & 65.5 \\
\hline & Advice given & 40 & 10.7 \\
\hline
\end{tabular}


There were no problems experienced by $79(75.2 \%)$ of the participants that had resumed sexual intercourse early (before six weeks postpartum), although some of them reported pain and/ or bruises during sexual intercourse 26 (24.8\%), bleeding 19(18.1\%), and abdominal pain $12(11.4 \%)$. Only $93(26.5 \%)$ were using a family planning method.

\section{Predictors of early resumption of the sexual intercourse after child birth}

Using the Pearson's chi-square test (Tables 3 and 4), predictors of early resumption of sexual intercourse after child birth were participant's religion $(p<0.01)$, level of education $(p<0.01)$, occupation $(p<0.01)$, parity $(p<$
$0.01)$, spouse's level of education $(p<0.01)$, age of the baby or time since delivery $(p<0.01)$, use of family planning $(p<0.01)$, breast feeding of the baby $(p<0.01)$, and mode of delivery $(p<0.01)$. On multivariate analysis, independent predictors of early resumption of sexual intercourse (Table 5) were occupation of the mother $(\mathrm{OR}=0.17$; CI 0.09-0.34; $p=0.000)$, parity ( $\mathrm{OR}=6.92$; CI 2.41-19.86; $p=0.000)$, education level of spouse $(\mathrm{OR}=$ 0.33 ; CI $0.011-0.103 ; p=0.000)$ and use of family planning methods (OR =17.03; CI 2.24-127.27).

\section{Discussion}

Many women had resumed sexual intercourse by 6 weeks postpartum. The finding is similar to that of others

Table 3 Factors associated with early resumption of sexual intercourse

\begin{tabular}{|c|c|c|c|c|}
\hline \multirow[t]{2}{*}{ Variable } & & \multicolumn{2}{|l|}{ Timing of resumption } & \multirow[t]{2}{*}{$P$ value } \\
\hline & & Before 6 weeks (\%) & After 6 weeks (\%) & \\
\hline \multirow[t]{3}{*}{ Age } & $15-20$ & $1(3.3)$ & $17(7.7)$ & 0.223 \\
\hline & $21-35$ & $54(88.5)$ & $203(91.9)$ & \\
\hline & $36-45$ & $5(8.2)$ & $1(1.6)$ & \\
\hline \multirow[t]{4}{*}{ Religion } & Protestant & $8(13.1)$ & $79(35.7)$ & 0.000 \\
\hline & Roman catholic & $45(73.8)$ & $119(53.8)$ & \\
\hline & Muslim & $8(13.1)$ & $8(3.6)$ & \\
\hline & Others & $0(0)$ & $15(6.8)$ & \\
\hline \multirow[t]{5}{*}{ Level of education by respondent } & No formal education & $2(3.3)$ & $6(2.7)$ & 0.000 \\
\hline & Primary & $22(36.1)$ & $52(23.5)$ & \\
\hline & Secondary & $21(34.4)$ & $161(72.9)$ & \\
\hline & Diploma & $1(1.6)$ & $2(0.9)$ & \\
\hline & Degree & $15(24.6)$ & $0(0)$ & \\
\hline \multirow[t]{2}{*}{ Marital status } & Unmarried & $3(4.9)$ & $15(6.8)$ & 0.772 \\
\hline & Married & $58(95.1)$ & $206(93.2)$ & \\
\hline \multirow[t]{4}{*}{ Occupation of respondent } & House wife & $21(34.4)$ & $163(73.8)$ & 0.000 \\
\hline & Self employed & $24(39.3)$ & $42(19.0)$ & \\
\hline & Civil servant & $8(13.1)$ & $1(0.5)$ & \\
\hline & Private & $8(13.1)$ & $15(6.8)$ & \\
\hline \multirow[t]{3}{*}{ Parity } & First & $0(0)$ & $24(10.9)$ & 0.000 \\
\hline & Second & $61(100)$ & $76(34.4)$ & \\
\hline & Third or more & $0(0)$ & $121(54.7)$ & \\
\hline \multirow[t]{9}{*}{ Highest level by spouse } & No formal education & $0(0)$ & $2(0.9)$ & 0.000 \\
\hline & & $16(26.2)$ & $58(26.2)$ & \\
\hline & Primary & & & \\
\hline & & $16(26.2)$ & $161(72.9)$ & \\
\hline & Secondary & & & \\
\hline & & $21(34.4)$ & $0(0)$ & \\
\hline & Diploma & & & \\
\hline & & $8(13.1)$ & $0(0)$ & \\
\hline & Degree & & & \\
\hline
\end{tabular}


Table 4 Obstetrical factors associated with early resumption of sexual intercourse

\begin{tabular}{|c|c|c|c|c|}
\hline \multirow[t]{2}{*}{ Variable } & & \multicolumn{2}{|l|}{ Timing of resumption } & \multirow[t]{2}{*}{$P$ value } \\
\hline & & Before 6 weeks (\%) & After 6 weeks (\%) & \\
\hline \multirow[t]{3}{*}{ Mode of delivery } & Vaginal no tearing & $53(86.9)$ & $152(68.8)$ & 0.009 \\
\hline & Vaginal with (episiotomy/tear ) & $8(13.1)$ & $50(22.6)$ & \\
\hline & Caesarean section & $0(0.0)$ & $19(8.6)$ & \\
\hline \multirow[t]{3}{*}{ Time from childbirth } & Less than 6 weeks & & $39(17.4)$ & 0.000 \\
\hline & $6-11$ weeks & $45(73.8)$ & $182(82.4)$ & \\
\hline & 12-24 weeks & $16(26.2)$ & & \\
\hline \multirow[t]{2}{*}{ Using family planning } & No & $16(26.2)$ & $183(85.5)$ & 0.000 \\
\hline & Yes & $45(73.8)$ & $31(14.5)$ & \\
\hline \multirow[t]{2}{*}{ Breast feeding the baby } & No & $8(13.1)$ & $0(0.0)$ & 0.000 \\
\hline & Yes & $53(86.9)$ & $221(100.0)$ & \\
\hline \multirow[t]{2}{*}{ Breastfeeding the baby exclusively } & No & $11(18)$ & $36(15.8)$ & 0.681 \\
\hline & Yes & $50(82)$ & 186 (84.2) & \\
\hline
\end{tabular}

$[9,10,22]$ who reported that the earliest time for resumption of sexual intercourse was 3 weeks while the latest time was at 13 weeks postpartum. Similarly, a study conducted in Uganda among women with HIV reported that $58 \%$ of women had resumed sexual intercourse within 6 weeks after childbirth [8]. Our study is in agreement with Perry [6], who reported that sexual intercourse can be resumed safely by the second to fourth week after birth, when bleeding has stopped and the episiotomy or laceration site has healed.

Our study shows that occupation of the mother was significantly associated with timing of resumption of sexual intercourse. This finding is similar to that of Radziah et al. [9] from Malaysia who found that mothers who earned more money had early resumption of sexual intercourse during their postpartum period compared to those who earned less money. Therefore, it can be inferred from other studies and ours that higher income is associated with early sexual resumption of sexual intercourse (before six weeks postpartum).

The finding that parity was significantly associated with timing of resumption of sexual intercourse after

Table $\mathbf{5}$ Logistic regression for early resumption of sexual intercourse after child birth on individual factors

\begin{tabular}{lclc}
\hline Characteristic & Odds Ratios & $95.0 \% \mathrm{Cl}$ & $P$-value \\
\hline Education & 1.69 & $0.67-4.23$ & 0.265 \\
Occupation & 0.17 & $0.09-0.34$ & 0.000 \\
Parity & 6.92 & $2.41-19.87$ & 0.000 \\
Level of education of spouse & 0.03 & $0.01-0.10$ & 0.000 \\
Occupation of spouse & 1.22 & $0.82-1.82$ & 0.324 \\
Time from childbirth & 3.74 & $1.18-11.86$ & 0.025 \\
Use of family planning & 17.03 & $2.24-127.27$ & 0.006 \\
\hline
\end{tabular}

child birth is in agreement with others [23] who found that women with few children resume sexual intercourse earlier than women who had many children. Regarding education level of spouse, our finding of a significant association with early resumption of sexual intercourse is similar to that of Osinde et al. [8], where women with male partners with a higher educational level resumed sexual intercourse earlier than six weeks postpartum.

Likewise, as in the study by Rowland et al. [23], the age of the baby was significantly associated with early resumption of sexual intercourse after child birth is similar to that of Rowland et al. [23]. The finding that use of family planning was associated with early resumption of sexual intercourse after child birth is similar to that of other studies $[8,9,17,23-25]$. The finding is contrary other studies $[8,26]$ which reported no differences in resumption of sexual intercourse among the women who were using postpartum contraception compared with those who were not.

Religion and cultural norms influence the timing of resumption of sexual intercourse, as noted in the study. Religion influenced resumption of sexual intercourse in a study from Cote d'Ivore [18] and the Gambia [18], where Islamic traditions prescribe 40 days of postpartum abstinence. A similar custom was reported in the Gambia in a predominantly Muslim population [18]. In Nigeria, $1 \%$ of women resume sexual intercourse due to cultural demand [10]. A study from Uganda [22] reported that different tribal customs influenced the timing of resumption of sexual intercourse within the early days of puerperium. In this study, some women resumed sexual intercourse early because they were fulfilling cultural demands. For instance, in some cultures it was believed that a woman was expected to resume sexual intercourse within the first week after delivery "so as to 
help in the healing of the wounds" and "to bring good health to the baby" [22]. The cultural practice of new mothers staying with their in laws or at their parents' homes after childbirth was also one way in which culture prohibited early resumption of sexual intercourse after childbirth $[9,10,15,22]$. In Tanzania, women were sometimes described as 'giving in' to men's sexual advances in order to protect their marriage, avoid divorce, or family violence, such as battering and rape, as men force them to have sexual intercourse against their will' [13]. Spousal pressure and fear that their spouse would leave them were cited as reasons for early resumption of sexual intercourse [8].

The mode of delivery might influence timing of resumption of sexual intercourse. Women who had vaginal delivery with stitches were far less likely to resume intercourse early compared to women who had a vaginal delivery without perineal stitches or who had caesarean sections $[15,22,23]$. Women who had a vaginal delivery were 3.6 times more likely to experience sexual problem(s) on resumption of sexual intercourse postpartum compared with those that delivered by caesarean section [10]. A study from India [25] found that the median time to restart intercourse after a normal vaginal delivery with episiotomy was 40 days postpartum compared to 10 days postpartum and after a caesarean section. The most common problems in the normal delivery group were decreased libido (80\%), sexual dissatisfaction (65\%), and vaginal looseness (55\%), while in the caesarean section group, the most common problems were vaginal dryness (85\%), sexual dissatisfaction (60\%), and decreased libido (35\%) [24]. Occurrence of dyspareunia in the postpartum year was more likely in women who had a vaginal delivery [22-25]. In contrast, a study from Iran [7] found no association between the mode of delivery and timing of resumption of sexual intercourse or dyspareunia during 2-6 weeks postpartum. While interest in sexual activity often decreases throughout pregnancy, it eventually returns to normal postpartum with average resumption of intercourse, ranging between 5 and 8 weeks after childbirth [27-29].

\section{Conclusion}

Over one in every five mothers resumed sexual intercourse before the recommended six weeks postpartum. Occupation of the mother, parity, level of education of the spouse, time from delivery and use of family planning were the significant determinants of early resumption of sexual intercourse after child birth.

\section{Competing interests}

The authors declare that they have no competing interests.

\section{Authors' contributions}

DKK, RCN and SNM conceptualized the review of the literature, conducted the literature search and synthesized the literature. OK, MOO, SN, AN and NK advised on the literature synthesis and participated in editing several versions of the draft manuscript. All the co-authors approved the final manuscript.

\section{Acknowledgements}

This literature review was part of a post-doctoral research project for DKK funded by SIDA through the Makerere University-Karolinska Institutet postdoctoral-research grants. The findings and conclusions of this article are those of the authors and do not necessarily represent the views of the funders or of Makerere University.

\section{Author details}

${ }^{1}$ Department of Nursing, School of Health Sciences, College of Health Sciences, Makerere University, P.O. Box 7072, Kampala, Uganda. ${ }^{2}$ Adult Health and Critical Care Department, College of Nursing, Sultan Qaboos University, P.O. Box 66Alkhod, PC 123 Muscat, Oman. ${ }^{3}$ Department of Obstetrics and Gynecology, School of Medicine, College of Health Sciences, Makerere University, P.O. Box 7072, Kampala, Uganda.

Received: 4 May 2015 Accepted: 23 October 2015

Published online: 19 November 2015

\section{References}

1. Ahman E, Zupan JN. Neonatal and perinatal mortality: country regional and global estimates. Geneva: World Health Organization; 2004.

2. World Health Organization. The world health report; Make every mother and child count, Geneva. 2005. http://www.who.int/whr/2005/whr2005_en.pdf

3. WHO. WHO Technical Consultation on Postpartum and Postnatal Care. Geneva, Switzerland: World Health Organization; 2010. p. 11-16. WHO/MPS/ 10.03. http://whqlibdoc.who.int/hq/2010/WHO_MPS_10.03_eng.pdf.

4. Adong $\mathrm{H}$. Knowledge, perceptions and practices in pregnancy and childbirth in Uganda: an exploratory study of Nangabo sub-county, Wakiso district, Uganda. Master of Arts Dissertation 2005; Makerere University. 2005. http://docs.mak.ac.ug/sites/default/files/

Adong\%2520Harriet\%2520MA_Soc\%2520Dissertation_electron.

5. Glazener CM. Sexual function after childbirth: women's experiences, persistent morbidity and lack of professional recognition. Br J Obstet Gynaecol. 1997;104(3):330-5.

6. Egbuonu I, Ezechukwu CC, Chukwuka JO, Ikechebelu Jl. Breastfeeding, return of menses, sexual activity and contraceptive practices among mothers in the first six months of lactation in Onitsha, South Eastern Nigeria. J Obstet Gynaecol. 2005;25:500-3.

7. Heidari M, Khoel EM, Kiani A. What happens to sexuality of women during lactation period. Pak J Med Sci. 2009;25(6):938-43.

8. Osinde MO, Kaye DK, Kakaire O. Influence of HIV infection on women's resumption of sexual intercourse and use of contraception in the postpartum period in rural Uganda. Int J Gynaecol Obstet. 2012;116(2):171-2

9. Radziah M, Shamsuddin K, Jamsiah M, Normi M, Zahari TH, Syimah AT, et al. Early resumption of sexual intercourse and its determinants among postpartum Iban mothers. Int J Reprod Contracept Obstet Gynecol. 2013;2(2):124-9.

10. Anzaku AS, Mikah S. Postpartum resumption of sexual activity, sexual morbidity and use of modern contraceptives among Nigerian women in Jos. Ann Med Health Sci Res. 2014;4:210-6.

11. WHO. Pregnancy, child birth, postpartum and new born care: A guide for essential practice. 2003. http://whqlibdoc.who.int/publications/2003/ 924159084x.pdf

12. Tamale S: Out of the closet: Unveiling sexuality discourses in Uganda. (2003).Feminist Africa: Changing Cultures; (2). Http://agi.ac.za/sites/agi.ac.za/ files/fa_2_standpoint_3.pdf

13. Mbekenga CK, Olsson P, Pembe AB, Draj E, Christensson K. Prolonged sexual abstinence after childbirth: gendered norms and perceived family health risks. Focus group discussions in a Tanzanian suburb. BMC Int Health Hum Rights. 2013;13:4.

14. Buhling KJ, Schmidt S, Robinson JN, Klapp C, Siebert G, Dudenhausen JW. Rate of dyspareunia after delivery in primiparae according to mode of delivery. Eur J Obstet Gynecol Reprod Biol. 2006;124(1):42-6. 
15. Ekabua JE, Ekabua KJ, Odusolu P, Agan TU, Etokidem AJ. Factors associated with contraceptive use and initiation of coital activity after child birth. Open Access JContracept. 2010;1:85-91.

16. Sule-Odu TA, Fakoya FA, Oluwole OA, Ogundahunsi AO, Olowu AO, Olanrewaju DM, et al. Postpartum Sexual Abstinence and Breastfeeding Pattern in Sagamu, Nigeria. Afr J Reprod Health. 2008;12(1):96-100.

17. Makanani B, Kumwenda J, Kumwenda N, Chen S, Tsui A, Taha TE. Resumption of sexual activity and regular menses after childbirth among women infected with HIV in Malawi. Int J Gynaecol Obstet. 2010;108(1):26-30.

18. Desgrées-du-Loû A, Brou H. Resumption of Sexual Relations Following Childbirth: Norms, Practices and Reproductive Health Issues in Abidjan, Côte d'Ivoire. Reprod Health Matters. 2005;13(25):155-63.

19. Ministry of Health Uganda (2012). Uganda Clinical Guidelines: National Guidelines of common conditions. The Republic of Uganda. http:// apps.who.int/medicinedocs/documents/s21741en/s21741en.pdf

20. Drake AL, Wagner, Richardson B, John-Stewart G. Incident HIV during pregnancy and postpartum and risk of mother-to-child HIV transmission: a systematic review and meta-analysis. PLoS Med. 2014;11(2):e1001608.

21. UNFPA. HIV Prevention in Maternal Health Services. Improving Womens' Health Worldwide; Engender Health. 2004. http://www.engenderhealth.org/ files/pubs/hiv-aids-stis/hiv_prev_training_gde.pdf

22. Odar $E$, Wandabwa J, Kiondo P. Sexual practices of women within six months of childbirth in Mulago hospital. Uganda Afr Health Sci. 2003;3(3):117-23.

23. Rowland M, Foxcroft F, Hopman MW, Patel R. Breast feeding postpartum immediately postpartum. Can Fam Physician. 2009;51:1366-7.

24. Borda MR, Winfrey W, Mckaig C. Return to sexual activity and modern family planning use in the extended postpartum period: an analysis of findings from seventeen countries. Afr J Reprod Health. 2010;14(4):75-82

25. Khajehei M, Zivsdlou S, Safari RM, Tabatabaee HR, Kashefi F. A comparison of sexual outcomes in primiparous women experiencing vaginal and caesarean births. Indian J Community Med. 2009;34(2):126-30.

26. Kelly LS, Sheeder J, Stevens-Simon C. Why lightning strikes twice: postpartum resumption of sexual activity during adolescence. J Pediatr Adolesc Gynecol. 2005;18(5):327-35

27. Byrd JE, Hyde JS, DeLamater JD, Plant EA. Sexuality during pregnancy and the year postpartum. J Fam Pract. 1998:47:305-8.

28. Signorello LB, Harlow BL, Chekos AK, Repke JT. Postpartum sexual functioning and its relationship to perineal trauma: A retrospective cohort study of primiparous women. Am J Obstet Gynecol. 2001;184:881-8.

29. Grudzinskas JG, Atkinson L. Sexual function during the puerperium. Arch Sex Behav. 1984;13:85-91.

\section{Submit your next manuscript to BioMed Central and take full advantage of:}

- Convenient online submission

- Thorough peer review

- No space constraints or color figure charges

- Immediate publication on acceptance

- Inclusion in PubMed, CAS, Scopus and Google Scholar

- Research which is freely available for redistribution 